\title{
Sartre y la interpretación dialéctica de la Revolución*
}

\section{Sartre and the dialectic interpretation of the revolution}

\author{
GaEtano Rametta \\ Università degli studi di Padova
}

Resumen. El texto se centra en ofrecer un análisis de la interpretación sartreana de la Revolución Francesa contenida en Crítica de la razón dialéctica. Por ello nociones como las de juramento, grupo en fusión, nación soberana, libertad-terror o nadificación, fundamentales en la lectura que el autor de El ser y la nada realiza de este hecho histórico, adquieren protagonismo en este ensayo y aparecen en él de forma recurrente. Son mencionadas asimismo las críticas de Lévi-Strauss a la propuesta hermenéutica de Sartre acerca de la Revolución y se compara ésta con la expuesta por Hegel en la Fenomenología del Espíritu.

Palabras clave: Sartre, Revolución francesa, juramento, grupo en fusión, serialidad
Abstract. The text focuses on offering an analysis of the Sartrean interpretation of the French Revolution which is contained in the Critique of Dialectical Reason. Because of that notions as oath, group in fusion, sovereign nation, freedom-terror or nihilation, that are all basic in the reading that the author of Being and Nothingness makes of this historical fact, become prominent in this essay and appear in it in a recurrent manner. Lévi-Strauss' criticism at Sartre's hermeneutical proposal on the Revolution is mentioned as well and this interpretation is finally compared with the one that Hegel puts forward in the Fenomenology of the Spirit.

Key words: Sartre, French Revolution, oath, group in fusion, seriality

\section{Lévi-Strauss crítico de Sartre}

En la Crítica de la razón dialéctica Sartre aspira a proporcionar las condiciones a priori para la inteligibilidad de la historia ${ }^{1}$. Es éste un a priori diferente

* Traducción de Lorena Rivera León. Título original: «Sartre e l’interpretazione dialettica della rivoluzione».

1 Cfr. J. P. Sartre, Critique de la raison dialectique, précédé de Questions de méthode, ed. de A. Elkaïm-Sartre, Gallimard, Paris, 1985. En lo que sigue, nos referiremos a la primera con la sigla $C R D$ y a las segundas con la sigla $Q M$. Dentro de los estudios sartreanos se está dando un renovado interés por la interpretación de la Revolución Francesa por parte del filósofo. Aparte de los congresos que se han celebrado durante el año en curso, $c f r$. el último Études sartriennes, n. ${ }^{\circ}$ 
al tradicional que es característico de la filosofía trascendental. No nos hallamos, de hecho, ante una reconstrucción de las condiciones de posibilidad de la experiencia histórica, sino ante una reconstrucción de sus condiciones de inteligibilidad a partir del dato insalvable de la constitución orgánica del ser viviente. Éste es tal en tanto que organismo, esto es, en tanto que relación fluida y recíproca entre partes que al reproducirse recíprocamente se sustentan tan sólo a condición de asimilar las sustancias de un ambiente. Pero este ambiente representa un conjunto de recursos sólo en sentido potencial. Le corresponde al organismo transformar el ambiente de manera que lo convierta en funcional para su supervivencia.

El ser humano no constituye una excepción. A diferencia de lo que sostiene Lévi-Strauss en la crítica a Sartre que cierra el Pensamiento salvaje ${ }^{2}$, entre hombre y naturaleza no se da tan sólo una fractura. Toda separación se sitúa siempre dentro de una inclusión más profunda, representada por el hecho de que el hombre es, ante todo, un ser viviente. Esto significa que la libertad, que está constituida para Sartre por la circunstancia de que el ser humano es por encima de todo «proyecto», es actividad de negación del dato externo sólo en la medida en que se sitúe dentro de la naturaleza y asuma positivamente su base orgánica como condición de su ejercicio.

Es éste el sentido de los largos análisis que Sartre dedica a la «necesidad» como condición fundamental del organismo. Sólo si se parte de que el hombre es un ser viviente, es posible comprender las diferencias entre el ser humano y el animal, así como el carácter dramático de la existencia humana. «Dramático» se emplea aquí en el sentido literal que remite al drân de los griegos, esto es, el significado de un actuar libre que en el ejercicio de su propia libertad suscita contra sí un destino adverso. Más que basándose en el criterio de una asunción inconsciente de modelos «animistas» - como todavía mantiene Lévi-Strauss ${ }^{3}$ - es en el sentido de la tragedia clásica como debería entenderse el vuelco dialéctico que partiendo del «grupo en fusión» lleva a los hombres a profundizar de nuevo en la serialidad, de la que intentará apartarles la puesta en común de sus fuerzas mediante el acto del juramento.

Según Sartre el juramento no es asimilable a un «contrato social». E1 hombre ha estado siempre socializado y aunque esto pueda parecer paradójico en relación con una visión que lo deforma y que aparece en la óptica de sus críticos, el filósofo francés opina que el ser humano nunca está verdaderamente solo. El porqué radica en que las formas elementales de la socialización integran al hombre en un conjunto de relaciones de carácter «serial». Lo que emerge en la serialidad es el destino, expresión de un tiempo cerrado en

12, 2007-2008: Sartre inédit, en el que se presentan dos manuscritos inéditos, uno sobre el nacimiento de la Asamblea nacional y el otro acerca de las nociones de libertad y de igualdad.

2 Cfr. C. Lévi-Strauss, La Pensée sauvage, cap. IX: Histoire et dialectique, en íd., Euvres, Bibliothèque de la Pléiade, Gallimard, Paris, 2008, pp. 822-849.

3 Véase Lévi-Strauss, op. cit., p. 827 y nota. 
el eterno retorno de su circularidad. La estructura de la serie es la de la recurrencia, en el sentido técnico y pertinente de la inducción matemática que rige, según Paetano, la construcción de los números enteros. El número lidera la serie, pero en él está contenido incluso el secreto de una potencia, que es inmanente a la multiplicidad de la serie misma, y al que le basta con hallar un detonante para activarse. La socialización serial se transforma entonces, mediante una auténtica metamorfosis, en el «grupo en fusión» que intentará consolidarse a través de la forma del juramento.

Tal y como veremos, el juramento no funda, pero trata de garantizar la supervivencia del grupo, sancionando la institución del individuo como «individuo común». Después de decenios de historia conceptual resultaría incluso demasiado fácil reprocharle a Sartre el carácter antinómico de esta categoría. Pero sería también, aparte de injusto, totalmente estéril. Hemos de leer al organismo en el individuo: es siempre el ser humano, en la medida en que constituye un ser viviente, el que se compromete en el juramento a conformar un grupo de acción junto a los demás. La originalidad y la cesura que establece el juramento no aparecen constituidas por el hecho de que este último deba cortar los puentes con la dimensión del organismo, sino por la circunstancia de que el organismo no es ya el fundamento de la acción y de la decisión. En la clave de la «crítica» dialéctica esto significa que la inteligibilidad del juramento no puede alimentarse de la referencia al organismo sino que, al contrario, el organismo se volverá inteligible en tanto que sujeto de acción sólo a partir de la constitución del grupo que lo incluye.

Hemos hablado de «constitución» y hemos aludido además a una «inclusión». Aquí pueden esconderse trampas. «Constitución» no significa de hecho «creación de la nada». En sentido genuino no es siquiera, como el contractualismo moderno pretendía, una «fundación». Para que sea efectivo, el juramento no sólo no ha de imaginarse como «acontecimiento» - a pesar de que precisamente en la Revolución Francesa encontramos el ejemplo quizá más célebre de un juramento que se ha querido, casi teatralmente, establecer en la forma explícita del acontecimiento--, sino que él presupone que el grupo se ha constituido $y a$. Si el juramento precede a la creación del «grupo en fusión», como en el caso de la Revolución Francesa, en la que el juramento del 20 de junio es anterior a la toma de la Bastilla del 14 de julio, es sólo de manera retroactiva, es decir, a partir de este hecho simbólico de emancipación de la serialidad, cuando el juramento asumirá su significado de umbral epocal.

Pero aquí se abre un doble problema, que en su primera vertiente concierne al significado de la Revolución Francesa por la construcción del aparato conceptual de Sartre. Este último se refiere a los episodios de la Revolución Francesa, que comenta en su libro, como a «ejemplos» que deberían limitarse a ilustrar los desarrollos dialécticos de su razonamiento. La cuestión no consiste en idear categorías para interpretar la Revolución, sino en utilizar la Revolución para ilustrar las categorías. ¿De qué categorías se trata? De las desarrolla- 
das de manera autónoma con respecto a la crítica de la razón dialéctica y cuyo estatuto consiste en proporcionar las condiciones a priori para la inteligibilidad de cualquier posible historia. De ello resulta que estas categorías deberán encontrar una aplicación que habrá de ser modulada según los casos en la interpretación de todo fenómeno histórico. La Revolución constituye sólo uno de los ejemplos posibles en los que la fecundidad de la crítica debería demostrar su eficacia en aras de la comprensión concreta de la historia. Otros ejemplos que Sartre privilegia son la evolución y las transformaciones de la clase obrera francesa desde los inicios del desarrollo capitalista posterior a la Revolución hasta la formación del obrero no cualificado hacia el final de los años cincuenta; o bien las sociedades «primitivas» estudiadas por Lévi-Strauss en las Estructuras elementales del parentesco ${ }^{4}$.

Se hace entonces inevitable formularse la pregunta de este último: ¿es realmente la Revolución tan sólo un ejemplo entre otros? ¿Son de verdad tan independientes de la Revolución las categorías de «grupo en fusión», de «juramento», de «hermandad»y «libertad-terror» que según Sartre constituyen las condiciones de inteligibilidad de cualquier y posible historia? Lévi-Strauss tiene razón. Sartre cae víctima de una ilusión que podría definirse como trascendental cuando pretende universalizar categorías formadas sobre la base de una experiencia histórica específica como la de la modernidad europea, así como ampliar su ámbito de validez hasta la inclusión de cualquier tipo de sociedad, civilización y época ${ }^{5}$.

En clave histórico-conceptual tenemos un claro ejemplo de proyección hacia atrás en el tiempo y de extensión generalizada en el espacio de ese complejo categorial y sistemático que podríamos resumir en la relación entre sujeto y libertad, y que en clave política ha sido traducido en la construcción artificial del orden político mediante el dispositivo de la legitimación y de la representación. Pero no es éste el lugar para efectuar un repaso de la génesis de las nociones de poder, soberanía y unidad política que han dirigido la formación de los Estados modernos y que han regido su ordenamiento constitucional hasta nuestros días ${ }^{6}$. Lo importante es comprender el estatuto de la Revolución en el discurso de Sartre y de captar el alcance de la polémica con

${ }^{4}$ Acerca de este último punto cfr., en particular, CRD, 574-598.

5 «En efecto, el problema planteado por la Crítica de la razón dialéctica puede reducirse a éste: ¿en qué condiciones es posible el mito de la Revolución Francesa? Y estamos dispuestos a admitir que, para que el hombre contemporáneo [en 1961 (N. del A.)] pueda desempeñar plenamente el papel de agente histórico, tiene que creer en este mito, y que el análisis de Sartre desprende admirablemente el conjunto de las condiciones formales indispensables para que este resultado quede asegurado» (C. Lévi-Strauss, op. cit., p. 832) [Ofrecemos aquí, al igual que en la nota 7, la traducción española del original francés citado en italiano por Gaetano Rametta: C. Lévi-Strauss, El pensamiento salvaje, trad. de F. González Aramburo, F.C.E, México, 1964, p. 368. (N. de la T.)]

${ }^{6}$ Cfr. para todas las contribuciones contenidas en G. Duso (ed), El poder: para una historia de la filosofía política moderna, trad. de S. Mattoni, Siglo XXI, México, 2005. 
Lévi-Strauss cuando éste le lanza al autor de la Crítica la imputación de caer en una mitología no tan diferente, en cuanto a estructura, de la que él había atribuido en su libro a las sociedades así llamadas «primitivas» ${ }^{7}$.

El mito es una forma de pensamiento pero, en el caso de Sartre, se trata de un pensamiento víctima de su pretensión de transparencia. A partir de esta pretensión surge un modelo único de razón; de este modelo de razón nace la autolegitimación de las categorías constituidas para valer en sentido universal y necesario; a partir de esta extensión de las categorías a todo sector del tiempo y del espacio aparece el ofuscamiento respecto de la matriz histórico-conceptual de esa misma pretensión de validez incondicionada. Y con todo: ¿es el discurso sartreano sólo un mito?

El propio Lévi-Strauss reconoce, aunque no sin ironía, la pertinencia de los análisis de Sartre siempre que éstos se entiendan como investigaciones acerca de las condiciones formales de la modernidad. Es ésta una indicación que puede desarrollarse, pero que conduce a un resultado diferente al de la crítica del gran antropólogo. Todo pensador concibe su distancia con los demás en relación a universos conceptuales y discursivos que no han sido creados a partir de la nada. Al proceder a la construcción de una filosofía original el autor crea también un dispositivo que debería hacerlo capaz de percibir qué le separa de autores pertenecientes a épocas distintas. Ya el empleo de la noción de «época» permite advertir la presencia de un discurso que no es separable de la formulación de cierta teoría de la historia impensable antes de la edad moderna. Sintetizando al máximo: toda filosofía, en la medida en que es hegelianamente «su propio tiempo apresado en el pensamiento» no puede saltar más allá de su tiempo y por tanto codificará la relación entre ella y el otro a partir de una autorreflexión que al distanciarse del universo conceptual de su época arrastra a éste inevitablemente consigo.

No creemos que Sartre merezca por esto un tratamiento más severo que otros, sobre todo teniendo en cuenta que poco tiempo después el propio Lévi-Strauss recibiría una crítica en la que se le reprocharían cuestiones no muy distintas, en esencia, de las que él le había recriminado a Sartre. Pero sobre Derrida, en tanto que autor de esta crítica ${ }^{8}$, se han vertido más reciente-

7 «Así desembocamos en la paradoja de un sistema que invoca el criterio de la conciencia histórica para distinguir a los «primitivos» de los «civilizados», pero que - a la inversa de lo que pretende - él mismo es ahistórico: no nos ofrece una imagen concreta de la historia, sino un esquema abstracto de los hombres haciendo una historia tal como puede manifestarse en su devenir en forma de una totalidad sincrónica. Por tanto, se sitúa ante la historia como los primitivos ante el eterno pasado: en el sistema de Sartre, la historia desempeña, muy precisamente, el papel de un mito. (C. Lévi-Strauss, op. cit., p. 832) [C. Lévi-Strauss, trad. cit., p. 368. (N. de la T.)]

8 Nos referimos evidentemente a J. Derrida, De la grammatologie, Éditions de minuit, Paris, 1967, cap. I de la segunda parte: La violence de la lettre: de Lévi-Strauss à Rousseau, pp. 149-202. [Existe traducción española: J. Derrida, De la gramatología, Siglo XXI, México, 1986. (N. de la T.)] 
mente otras críticas desde perspectivas que han creído ver en la deconstrucción el último refugio de la razón eurocéntrica ${ }^{9}$. Podríamos apostar algo al hecho de que, también en este caso, se tratará de un «último» sólo relativo a la cronología de nuestra actualidad.

De esta manera podemos afrontar la segunda faz del problema. Si se admite que la Revolución Francesa no constituye para Sartre un ejemplo entre otros, sino que juega en cambio el papel de auténtica matriz conceptual de su construcción filosófica, ¿qué fecundidad hermenéutica posee esta construcción cuando se hace valer en relación con la interpretación de la Revolución? Esta pregunta se subdivide a su vez en dos cuestiones. En primer lugar: ¿en qué nivel debe situarse este interrogante para que pueda hallar respuestas pertinentes?

La obra de Sartre no es un trabajo de historia, ni de economía o sociología: es una obra de filosofía en la acepción «crítica» que el mismo Sartre ha querido explícitamente definir. Habrá que determinar por tanto la productividad de los análisis sartreanos en relación con la curvatura filosófica impresa a los «acontecimientos» de la Revolución por parte del filósofo francés. En otros términos, lo que se valorará es el tipo de cariz, o el ángulo específico de distorsión filosófica que los episodios «históricos» de la Revolución reciban una vez «reflejados» en el espejo creado por el discurso filosófico de Sartre. Es aquí donde se deberá hacer resaltar el elemento diferencial que distingue la interpretación de la Revolución por parte de Sartre del gran modelo hegeliano.

La segunda cuestión se deriva de la primera y concierne a la importancia filosófica global que la Revolución Francesa asume en los dos discursos que hemos escogido como paradigmas de su interpretación dialéctica. ¿Qué pone de manifiesto la Revolución? ¿Qué dice de la época moderna o de la historia en su totalidad? Y por último, ¿qué implicaciones reviste para el ejercicio mismo de la filosofía en nuestros dos autores?

\section{Grupo en fusión y nación soberana}

Sièyes y Robespierre: si tuviésemos que rastrear hasta dar con los protagonistas de la exposición sartreana de la Revolución, sacaríamos seguramente a colación por su importancia los dos nombres indicados. Partamos del primero. Sièyes figura sólo en dos lugares de la Crítica de la razón dialéctica, pero ambos son decisivos ${ }^{10}$. El autor del celebérrimo Qu-est-ce que le Tiers Etat? es visto por Sartre como quien registra, en vísperas de la explosión revolucio-

9 Cfr. la distinción entre deconstrucción «académica» y deconstrucción «militante» en el último capítulo del libro de G. C. Spivak, A critique of post-colonial reason: toward a history of vanishing present, Harvard University Press, Cambridge (Ma)-London, 1999.

10 Cfr. CRD, 466 y 484. 
naria ${ }^{11}$, el carácter «apocalíptico» de los acontecimientos en curso ${ }^{12}$. Así, en el eslogan según el cual el Tercer Estado es todo pero no cuenta nada lee Sartre la disolución de la serialidad como subordinación del Tercer Estado a la monarquía, a la nobleza y al clero. Sin embargo, la nada que Sièyes le atribuye al Tercer Estado en términos de libertad no es tan sólo una nada pasiva, ya que a través del Apocalipsis revolucionario encuentra la vía para su expresión en términos de nadificación activa. Puesto que «formalmente», o sea al nivel de las relaciones políticas codificadas en el Antiguo Régimen, el Tercer Estado es «nada», pese a ser «materialmente», es decir desde el punto de vista de las actividades sociales y económicas que producen la riqueza y potencia del Reino de Francia, «todo», resulta evidente que el cambio radical de esta «nada» de «Estado» pasivo (o «práctico inerte» en el lenguaje de esta Crítica) a «actividad» deberá producirse en términos de «nadificación», es decir, justamente a la manera de desleimiento o disolución apocalíptica de las relaciones hasta entonces existentes.

Es con esta nadificación con la que Sartre hace corresponder la concepción moderna, es decir destructiva del antiguo ordenamiento estamental, de la Nación soberana. En esta última no sólo las clases no tendrán ya derecho a existir, sino que en el paso de la burguesía de Tercer Estado a totalidad de la nación (juramento del Jeu de Paume), se realiza un salto decisivo también en relación con la temporalización de la experiencia histórica. El juramento produce de hecho una fractura histórica no sólo en términos de subjetivación, es decir mediante la autoconstitución de un nuevo sujeto colectivo (la Nación soberana), a partir de la «metamorfosis» y del abandono de su vieja envoltura estamental; sino que comporta también una transformación radical en las coordenadas de la orientación temporal, en las que la transmisión del orden a partir del pasado («tradición») es sustituida por el primado del futuro como tiempo «vacío» pero, precisamente por ello, aún del todo «por hacer» ${ }^{13}$.

En otros términos, a la anulación del ordenamiento estamental (nadificación de carácter espacial) le corresponde en el plano del tiempo la dimensión de lo que todavía no es ni ha sido nunca (el futuro como dimensión de la «nadificación» temporal). Dado que el futuro es «nada», de igual manera que en el Antiguo Régimen el «Tercer Estado» no contaba nada, ahora que es el primero el que se ha convertido en «nada» puede por fin el «Tercer Estado» contar como «todo»: como aquel «todo» que en realidad ya era, pero como el cual no contaba.

11 Recordamos que el libelo de Sieyès fue redactado a finales del año 1788 y publicado en enero de 1789: en el intervalo crucial, por tanto, que va de la convocatoria de los Estados generales ( 8 agosto 1788) a su reunión (5 de mayo del año siguiente).

12 Sartre retoma la idea del Apocalipsis de la novela de Malraux sobre la guerra civil española L'Espoir (1937). [Hay traducción española de la novela: A. Malraux: La esperanza, trad. de J. Bianco, Cátedra, Madrid, 1995. (N. de la T.)]

13 "À créer», CDR 484 (en cursiva en el texto). 
Al vacío que se le abre de frente y de espaldas, el «Tercer Estado» responde con una invención que es a un tiempo lógica y ontológica. Es lógica por la supresión de la antigua sociedad de clases que comporta la idea moderna de la Nación soberana y que se realiza a partir de ella; pero es también, y en este contexto lo es ante todo, una invención ontológica: invención porque el nuevo sujeto común que nace lo hace justamente por autoconstitución. Pero entonces, ¿no estamos volviendo al modelo iusnaturalista de la génesis del sujeto colectivo a través de la creatio ex nihilo? No exactamente, puesto que el Tercer Estado era ya el todo, y mediante el juramento del Jeu de Paume no hace sino ponerse como aquello que ya era.

De este modo Sartre nos da la posibilidad de complicar la lectura que Koselleck hace de la Revolución como «umbral» ${ }^{14}$ en la medida en que a este umbral se le atribuya un valor puramente nihilista, esto es, justo de autoconstitución de un nuevo sujeto a partir de la nada. Sartre sustituye el modelo de la fractura pura y simple por el de la metamorfosis: y la metamorfosis no sólo comporta una forma que ya existía, aunque ahora, a partir del acto constituyente, se la reconozca como una nuez o una cáscara vacía, sino que implica también una «sustancia» que aquella forma resguardaba y de la cual puede desembarazarse ahora, pero sólo ahora, como de una protección inútil. Es evidente que a la mutación de la forma le corresponde también una nueva sustancia. La nueva sustancia es la Nación soberana, que en la novedosa figura de la representación («una persona, un voto») debería hallar la forma que le resultara adecuada. Pero aquí surgen nuevos problemas.

La nación es un concepto de carácter expansivo tanto en sentido espacial como temporal. En sentido espacial porque habiendo eliminado todo supuesto en relación con los ordenamientos constituidos, no puede tolerar la subsistencia de diferencias independientes del movimiento de creación de la nación misma. En esta primera fase de afirmación del concepto no tocará pues rechazar la diferencia en cuanto tal, sino sólo la diferencia en tanto que presupuesta. Esto significa que la expansión de la nación se detendrá sólo cuando la eliminación de las diferencias, en tanto que presupuestas a la nación soberana, se haya completado. Sólo entonces, en el nuevo espacio de la soberanía entre libres e iguales conformado por la nación, podrán determinarse otra vez, desde su seno, diferencias en tanto que articulaciones del cuerpo soberano. Pero, como hemos visto, el carácter expansivo de la nación asume, de manera necesaria, también un carácter temporal: el tiempo de la nación está orientado al futuro, hacia lo que todavía no existe, dado que lo que ya existía ha quedado destruido en el movimiento de autoconstitución de la nación misma.

14 Cfr. en particular R. Koselleck, Vergangene Zukunft. Zur Semantik geschichtlicher Zeiten, Suhrkamp, Frankfurt am Mainz, 1979. [Existe traducción española: Futuro pasado. Para una semántica de los tiempos históricos, trad. de N. Smilg, Paidós, Barcelona, 1993. (N. de la T.)] 
Así pues, este doble carácter expansivo de la nación sólo es posible mediante la activación política de sus miembros. Estos últimos, unidos en el juramento que ha instaurado el nuevo sujeto como sujeto común, se han impregnado del nuevo carácter de la comunidad, aunque no hayan perdido el estatuto que los distingue como seres vivientes, esto es como organismos. El carácter práctico del organismo, dirigido en primer lugar a la satisfacción de la necesidad y por tanto a la transformación de la materia inorgánica mediante la actividad del trabajo, se halla ahora potenciado por el hecho de que el organismo del individuo no está ya vinculado al tiempo repetitivo de la serialidad que le es impuesta por el material «práctico-inerte» del mundo-ambiente. Mejor dicho, esta sumisión al «reino de la necesidad» está ahora integrada y sublimada dentro de un «reino de la libertad» en el que cada individuo se comporta como individuo «común», y el organismo se convierte en función subordinada a la actuación de esta libertad compartida.

Es aquí donde encuentra su riqueza de significado histórico-conceptual la tercera de las palabras de orden a las que la Revolución Francesa vinculó su destino: la fraternidad. El término, que habitualmente designa el vínculo contingente entre dos o más organismos nacidos de los mismos padres, se encuentra aquí desligado de la accidentalidad del caso y al mismo tiempo aupado al segundo escalón de una solidaridad que se da porque ha sido decidida y conscientemente querida. El hermano es el otro que ha pronunciado conmigo el juramento de una fidelidad recíproca que no compromete ni al yo ni al tú, sino a lo que Sartre llama el «tercero». Ni el yo ni el tú bastarían para llevar a cabo la fórmula del juramento, ya que sólo en la medida en que cada uno llame como testigo de sí al otro en calidad de tercero podrá este uno ser llamado por el otro a atestiguar su compromiso en calidad de «otro» tercero. Sólo en la medida en que cada uno sea testigo del otro como «tercero» podrá este último ejercer como testigo de la fidelidad que le haya sido jurada por el primero. El yo y el tú se convierten así en un «nosotros» que no aparece ya formado ni por un yo ni por un tú, sino por una multiplicidad de «terceros».

Ahora bien, ¿cómo podrá resistir la representación la onda de choque de esta instancia participativa? Las laceraciones de la Asamblea, que se establecerá en París a partir del 12 de octubre después de haber sido proclamada nacional (17 de junio) y constituyente ( 9 de julio), encuentran aquí, en la tensión entre dinámica expansiva de la nación soberana y organismo formal de la nueva representación, su punto de origen. Pero no se trata, evidentemente, de contradicciones entre simples conceptos. Entre el 20 de junio y el 12 de octubre tiene de hecho lugar el episodio crucial de la primera fase de la Revolución, que es al mismo tiempo la «jornada» en la cual Sartre se detiene con mayor atención: el 14 de julio, la «toma de la Bastilla» ${ }^{15}$. Es el ejemplo primario de cómo se forma un «grupo en fusión» y permite poner de manifiesto

15 Cfr. CRD, 455-468. 
su estructura de fondo desde la fase incipiente de su constitución hasta el momento en que, al desaparecer la participación directa en el suceso y la conquista del objetivo, el «calor» que había cohesionado al grupo en una única formación de mil personas vuelve a «enfriarse» y a exponerse a la toma de la serialidad.

Estamos ante páginas que merecerían un comentario aparte y que son capaces de suscitar por sí solas la perplejidad que se experimenta al constatar que, incluso en estimables antologías de las principales interpretaciones de la Revolución, Sartre no figura ni siquiera en el índice de nombres ${ }^{16}$. ¿Qué es lo que emerge del análisis sartreano? Ante todo la concreción de una configuración material: no se trata sólo del hecho de que tropas armadas habrían podido irrumpir por un lado del barrio ni tampoco del hecho de que la Bastilla se erigiese en el lado opuesto como símbolo de una opresión que se había hecho ya intolerable, sino de la combinación entre entrada posible de las tropas por una parte y presencia de la fortaleza por la otra: y de la fortaleza no simplemente como símbolo de la opresión, sino como obstáculo potencial a una vía de huida que resultaba imposible debido al uso eventual de los cañones presentes en ella.

Entre estos dos fuegos se despliega la distribución espacial del barrio como estructura práctico-inerte que devuelve al «pueblo», como su destino inminente, la amenaza de una masacre siempre posible. Pero para que esta disposición espacial adquiera el significado de una «amenaza» se hace necesaria una interpretación que la estructure como tal, esto es, que inscriba la combinación tropas-fortaleza en la ordenación espacial del barrio de manera que transforme a ésta última de mera configuración «práctico-inerte» en potencial fuente de nadificación. Y para que esta interpretación se produzca se requiere lo que Sartre define como una «exis», una disposición de ánimo que presente resistencia y que al mismo tiempo califique como amenaza la combinación tropas-fortaleza que se proyecta sobre la disposición «práctico-inerte» del espacio. Sólo a partir de esta exis puede acontecer la que Sartre define como «détermination hodologique de l'espace» ${ }^{17}$. Expresado en otros términos, la transformación en configuración dinámica de aquella determinación que, en una percepción contemplativa, se presentaría simplemente como yuxtaposición de las masas de las viviendas en el espacio. Éste se convierte en un conjunto de «calles» potencialmente transitables, ya sea por las tropas en el caso de que decidan atacar o por la población en el supuesto de que optase por huir por la parte opuesta.

${ }^{16}$ Cfr. L'albero della Rivoluzione. Le interpretazioni della Rivoluzione francese, a cura di B. Bongiovanni e L. Guerci, Einaudi, Torino, 1989. Como si no hubiese suficiente, Sartre es omitido también del listado de los excluidos (cfr. op. cit., p. XXIV).

$17 C R D$, 462. [«[...] determinación hodológica del espacio [...]», en J. P. Sartre, trad. cit., p. 23. (N. de la T.)] 
Pero precisamente en el momento mismo en que se abre la posibilidad, el carácter practicable del camino se le revela a la población del barrio como algo negado. Por un lado se cierne como inquietante posibilidad la irrupción de las milicias; por el lado contrario la amenaza de cañoneo aparece como más oscura y opresora debido al valor simbólico de la fortaleza. No obstante, queda por explicar el porqué de esta propensión al miedo. ¿Qué debería incitar a las tropas a entrar en el barrio? ¿Por qué deberían los cañones de la Bastilla ponerse de repente en funcionamiento? ¿Qué es lo que induce al pueblo a leer en el espacio su aniquilación anticipada?

El 12 de julio sucedió algo: algunos motines fueron contenidos en las Tullerías y la noticia de estos sucesos violentos se difundió por el barrio de Saint-Antoine reforzada por el eco de otro hecho violento en el que se había visto plenamente implicado el barrio, y que había sido protagonizado por tropas que habían penetrado en él desde la parte noroeste, la misma desde la cual se temía entonces una nueva irrupción, ya que en aquel momento la violencia se había desencadenado otra vez contra el pueblo en las Tullerías y no se veía por qué debería detenerse a las puertas del barrio de Saint-Antoine, donde ya había sido empleada para sofocar las manifestaciones del 17 de abril precedente y tan cercano...

Éste es el tipo de razonamiento que pone de manifiesto la pasividad propia de una socialización serial: tenemos el rasgo recurrente de la argumentación, su carácter proyectivo y el mecanismo de autoconfirmación del miedo ligado a la estructura circular, que reproduce la violencia prefigurada al final del razonamiento como confirmación del miedo. Es ésta una disposición originaria que percibe en el suceso cercano (la represión de las Tullerías) el eco de un acontecimiento anterior (la represión del 17 de abril) y que proyecta ambas cuestiones en el plano simbólico y fantasmal en el que la exis del «terror» gobierna la organización del discurso, elevándolo a la dimensión de una argumentación imaginaria.

La imagen fantasmal del Otro, producida por el cortocircuito entre un futuro temido y un pasado que todavía concierne, proporciona el detonador que hace prender la mecha de la revuelta y que invierte el sentido de la materialidad del espacio, que hasta entonces se había sufrido de manera pasiva como serialidad de lo práctico-inerte, transformándola en distribución fluida de acciones y de papeles coordinados de manera espontánea por un objetivo común: la «toma de la Bastilla». Este cambio radical produce la conversión del espacio en tiempo: la disposición material del barrio se convierte en apoyo para la diferenciación del grupo en fusión e imprime a la situación una temporalización marcada por la experiencia vivida por los sujetos. Pero la experiencia de los sujetos se había dado hasta entonces bajo el dominio de lo práctico-inerte. Por lo tanto, temporalizar esto significará transformar la categoría de la «escasez», dominante en la esfera de lo práctico-inerte, en clave temporal. Entonces ya no será el pan o la libertad lo que falte, sino el tiempo, y la ausencia de tiempo, vivida 
bajo el signo del miedo, le proporciona a la situación el carácter vivido de la urgencia: "L'urgence vient alors de la rareté du temps» ${ }^{18}$.

El pueblo verifica una suerte de silogismo práctico que acontece bajo el signo de la precipitación: si los soldados atacan el barrio por su lado descubierto habrá que defender este flanco con las armas. Pero las armas están en la Bastilla, por lo cual se hace necesario apresurarse a tomarla antes de que a alguien se le ocurra irrumpir en el barrio. Es algo semejante a lo que Lacan había llamado «aserción de certeza anticipada» ${ }^{19}$, y que también en este caso consiste en traducir una posibilidad (la irrupción de las tropas) en la absoluta certeza de que esto puede suceder e incluso de que está ya acaeciendo. Se trata por tanto de acelerar ulteriormente el suceso que está en camino de acontecer. Y la necesidad de esta aceleración implica una insuficiencia constitutiva del tiempo. La acción está siempre retrasada respecto de aquello que debe preceder, anticipándolo: el tiempo nunca basta, pero no porque sea demasiado poco, sino porque es siempre demasiado. No será nunca excesivamente pronto para atacar la Bastilla; no será nunca demasiado pronto cuando la hayamos conquistado; no será nunca suficientemente pronto para entrar en posesión de sus armas.

La aceleración del tiempo, convertida en rasgo caracterizador de la modernidad, no puede por tanto separarse de la formación del grupo en fusión: pero no de un grupo en fusión cualquiera, sino de ese grupo en fusión, determinado en esa contingencia histórica y estructurado a partir de esa situación determinada.

La atención a la singularidad concreta del acontecimiento, que ya en Question de méthode Sartre había reivindicado como propia de su peculiar existencialismo en oposición al envaramiento en la escolástica del marxismo, le permite hacer emerger las fracturas conceptuales a partir de la reconstrucción histórico-fenomenológica de la experiencia de los sujetos destinados a su vez a convertirse en «casi-objetos», es decir, en productos del acontecimiento que ellos mismos han provocado.

La experiencia de la velocidad pasa a ser algo más que una constatación histórico-conceptual. Confirma por una parte la incompatibilidad entre «crítica» dialéctica y filosofía de la historia, produciendo una fractura significativa en la autocomprensión que la filosofía contemporánea de la Revolución Francesa había dado de ella; y por otra parte conmensura el significado de la Revolución de acuerdo con la lógica específica de la acción que se desarrolla en ella. La temporalización del acontecimiento depende de hecho de la temporalización específica que el grupo imprime a su experiencia en el momento mismo en que el acontecimiento se produce. La motivación nega-

$18 C R D$ 464. [«La urgencia proviene entonces de la rareza del tiempo», en J. P. Sartre, trad. cit., p. 24. (N. de la T.)]

19 Cfr. J. Lacan, Écrits, Éditions du Seuil, Paris, 1966, pp. 197-213. 
tiva, que produce el miedo, se transforma en movimiento constituyente del grupo en fusión.

Aplicando de nuevo a Lacan a la lectura sartreana se puede mostrar cómo la prisa que caracteriza a la acción del grupo se relaciona sólo en un primer momento con el temor a una agresión por parte del Otro (en este caso, las tropas de la formación contraria). A partir de este detonador la «aserción de certeza anticipada» se convierte en modalidad de constitución inmanente del grupo mismo. No es sólo el terror a ser masacrado lo que me induce a correr hacia la Bastilla, sino el hecho de que leo el mismo terror en el rostro de mi vecino de casa o de tienda, quien a su vez lo ve confirmado en mí mismo y en sus vecinos.

Es entonces cuando el terror se convierte en un vínculo positivo. Llegados a este punto, todavía no se ha movido nadie, pero cada uno lee en el otro la exigencia de una defensa como un interés que nadie podría satisfacer por sí mismo. Al adelantar cada cual la irrupción entonces tan sólo imaginada de las tropas, anticipa el movimiento del otro en búsqueda de las armas que están depositadas en la Bastilla: antes incluso de ver que el otro parte soy yo el primero en correr en dirección a la fortaleza. Pero el otro hace exactamente lo mismo que yo: al adelantar la irrupción de las tropas también él anticipa el movimiento, del que yo he hecho ademán, de correr hacia la Bastilla. Habiendo decidido ambos anticipar la carrera del otro resulta que acabamos los dos corriendo en la misma dirección y nos damos además cuenta de que no somos los únicos, pues junto a nosotros, por una lógica inexorable de la libertad, está corriendo la población de todo el barrio.

Cuando el delegado convencional afirma en la prisión en la que fue recluido después de Termidor que todavía no entiende exactamente qué es lo que sucedió porque todo acontecía «con otra velocidad» ${ }^{20}$, no sostiene sólo que la lógica de los acontecimientos se había transformado en una instancia dominante e incomprensible para sus protagonistas ${ }^{21}$, sino que la experiencia de éstos era demasiado rica para poder quedar reducida a los principios de una explicación racional. Si es cierta la afirmación de Sartre de que la lógica de la acción es transparente sólo en el momento en que puede ser reducida a la praxis de un organismo individual, se presenta entonces una irreductibilidad de la acción de grupo a la acción de los sujetos particulares que promueven ese grupo y en el cual participan. Es éste el síntoma no sólo de una especificidad que distingue las acciones de una comunidad de las de un individuo, sino de una tensión interna dentro del orden conceptual del pensamiento de Sartre en su conjunto.

20 «[...] avec une autre vitesse», en cursiva en el original (cfr. CRD, 491). [«[...] con otra velocidad», en J. P. Sartre, trad. cit., p. 55. (N. de la T.)]

21 Es ésta la tesis, reducida a lo esencial, de H. Arendt, On Revolution, Viking Press, New York, 1963. [Hay traducción española: H. Arendt, Sobre la revolución, trad. de P. Bravo, Alianza, Madrid, 1988. (N. de la T.)] 
De hecho, la lógica implicada en la organización del libro del filósofo francés da en identificar como dialéctica «constituyente» la del individuo particular, ya que sería la única dotada de la característica de la «autotransparencia» - o, como también lo expresa el propio Sartre, de «translucidez». Cuando la combinación de las acciones individuales se da por simple sumatoria, constituye los «colectivos», mientras que cuando genera una compenetración del tipo «toma de la Bastilla» produce el «grupo en fusión».

Ahora bien, la lógica del grupo en fusión debería ser reductible a la del organismo práctico individual, porque el grupo reconvierte algo múltiple en unidad. Por el contrario, se descubre que la inteligibilidad que la unidad posee para el filósofo que la estudia no coincide con la inteligibilidad que tiene para los sujetos particulares que componen ese grupo. A partir de aquí Sartre extrae la conclusión de que lo que no les es posible a los sujetos sí que se convierte en tal para el filósofo siempre que éste abandone la ilusión en la que caen como víctimas los protagonistas del acontecimiento, los leader que surgen de la institucionalización progresiva del grupo y también los filósofos que pretenden inscribir ese suceso en el marco más amplio de una filosofía de la historia.

Este tipo de espejismo tiene un nombre: «hiperorganismo», esto es, proyección sobre el grupo del modelo de compenetración entre el todo y sus partes que cada cual encuentra realizada en sí mismo como ser viviente. Es la ilusión que las filosofías idealistas comparten con el marxismo dogmático del período estalinista y que lleva a hipostasiar un sujeto-sustancia colectivo como principio, sentido y sobre todo actor de la historia.

Las críticas de Sartre a la noción de hiperorganismo no han perdido un ápice de su validez, pero son justamente ellas las que sitúan al filósofo parisino en una encrucijada: o descubrir en la lógica de la acción llevada a cabo en común por una multiplicidad de sujetos a partir de la formación de un grupo en fusión una lógica irreductible a la lógica de la acción individual, pero no por ello menos inteligible; o bien mantener que el único modelo posible de inteligibilidad de la acción es el proporcionado por la praxis individual, y servirse por tanto de esta última para mostrar el fracaso inevitable al que está abocada cualquier acción común en tanto que dialéctica no ya constituyente, sino meramente «constituida».

Es innegable que esta última es la tendencia dominante en la concepción sartreana. Pero variaciones significativas presentes en el texto ${ }^{22}$, en las que

22 «La praxis commune est dialectique dès le niveau le plus élémentaire (celui du groupe en fusion): elle totalise l'objet, poursuit un but total, unifie le champ pratico-inerte et le dissout dans la synthèse du champ pratique commune. [...] Il convient en outre de remarquer qu'elle ne présente pas en elle-même les caractères spécifiques de la dialectique individuelle en tant que libre developpement d'un organisme pratique. La praxis commune [...] n'est pas en elle-même une simple amplification de la praxis d'un individu» (CRD, 508-509). Estos pasajes parecen aludir a la necesidad de arrojar luz sobre la racionalidad dialéctica especifica de la acción de grupo «hasta el nivel más elemental», pero quedan literalmente desmentidos por lo que Sartre había escrito pocas páginas antes: «[...] l'action commune, au niveau élémentaire, ne présente 
intentaremos profundizar en otro lugar, dejan vislumbrar la posibilidad de otra orientación de pensamiento, ampliamente presente en el texto mismo de la Critique. Está claro que el grupo en fusión, constituido durante la aventura de la conquista de la Bastilla, sucumbe, tan pronto como ha conseguido su objetivo, a un proceso de «enfriamiento» progresivo que amenaza con escindir los lazos que se habían estrechado provocando la reducción de lo múltiple a unidad: siendo también ésta, como hemos visto, una unidad de acción diferenciada, pero de manera fluida y aún no institucionalizada.

¿Qué es en cambio lo que sucede una vez que se ha realizado la «toma de la Bastilla»? El pueblo acaba paseando entre las ruinas de la fortaleza destruida y toma posesión de un símbolo, reducido ahora a la inercia de su estricta materialidad. La opresión no era sino un montón de piedras. Pero al pisar las ruinas de la fortaleza, el grupo no sólo celebra su triunfo, sino que ve asomarse una nueva inquietud, un renovado miedo: el de su disolución. Las ruinas le devuelven al pueblo la imagen del resultado de su gesta, pero en el resultado la hazaña aparece reflejada como algo pasado. La acción que ha alcanzado su objetivo se encuentra neutralizada por éste y el gesto que celebraba la libertad del grupo en fusión se ve reflejado en un objeto que le confirma el hecho de que ha sucedido realmente.

El juramento es la «invention pratique» ${ }^{23}$ mediante la cual el grupo se da cuenta, en el momento en que descubre que ha sobrevivido a su acción, de que tiene las horas contadas, ya que su existencia no era más que su praxis. Pero el grupo quiere sobrevivir más allá de la gesta y del hecho de que ésta se haya realizado. El juramento le garantiza al grupo su supervivencia en el momento mismo en que la decisión de sobrevivir apunta al hecho de que el destino del grupo está marcado. Toda la vida estaba de hecho en la acción y que el grupo quiera sobrevivir a la acción significa que desea proseguir una vida que ya no es ni puede ser la de antes.

Sartre interpreta la Revolución en el marco de esta lógica trágica: una acción ejemplar (la «toma de la Bastilla») se encuentra atrapada entre por una

pas de différences essentielles avec l'action individuelle [...]» (Cfr., p. 503), y confirma inmediatamente: «[...] la praxis non différenciée retient en elle les caractères de l'action individuelle en les amplifiant» (Cfr., p. 543).

[Ofrecemos aquí la traducción castellana de los tres pasajes citados en francés en esta nota a pie de página: (1) «La praxis común es dialéctica desde el nivel más elemental (el del grupo en fusión): totaliza al objeto, persigue un fin total, unifica el campo práctico-inerte y lo disuelve en la síntesis del campo práctico común. [...] Conviene señalar, además, que no presenta en sí misma las características específicas de la dialéctica individual en tanto que libre desarrollo de un organismo práctico. La praxis común [...] no es en ella misma una simple ampliación de la praxis de un individuo», J. P. Sartre, trad. cit., vol. 2, p. 74; (2) «[...] la acción común no presenta diferencias esenciales con la acción individual en el nivel elemental [...]», J. P. Sartre, trad. cit., vol. 2, p. 68; (3) «[...] la praxis no diferenciada retiene en ella las características de la acción individual y las amplifica», J. P. Sartre, trad. cit., vol. 2, p. 111. (N. de la T.)]

${ }^{23}$ CRD 519, en cursiva en el texto. [«[...] invento práctico», en J. P. Sartre, trad. cit., p. 85. (N. de la T.)] 
parte la necesidad de la representación, que separa la acción de su autor y le expropia al pueblo la soberanía que parecía al alcance de la mano y conquistada finalmente por el grupo en fusión; y por otra parte el «destino» que ella misma llama contra sí cuando decide sobrevivir y descubre en el juramento el único modo de hacerlo. El grupo pasa de ser «grupo de sobrevivencia» a convertirse en «grupo estatutario» en tanto que está ligado al vínculo del juramento. Éste comporta un estatuto que, si no fuera porque tememos un exceso de manierismo, podríamos definir como el status de un «estado»: una condición determinada de grupo quiere obtener para sí estabilidad y permanencia en el tiempo, esto es, convertirse en «estado». Y para consolidarse como estado, en el sentido de una condición estable y duradera, se dota de un «estatuto» que al principio se halla enteramente contenido en el juramento, pero que está destinado a pasar de juramento a «organización» en el sentido de reparto de deberes y funciones; y que se convertirá por tanto de «organización» en «organismo». Resulta singular esto que acontece cuando el grupo separa la «función» del individuo que la ejerce, esto es, de la praxis concreta que, como tal, no puede dejar de remitir a un organismo práctico en el sentido de que éste es capaz de acción.

De la organización a la institución; de ésta al sistema institucional que todos conocemos con el nombre de Estado; y de éste al monopolio de la soberanía como única instancia legítima en el ejercicio de la violencia para el mantenimiento del orden. El orden se basa en la ley, pero la ley se basa en una ficción llamada «representación». Volvemos así a Sieyès en la medida en que la noción de «poder constituyente» vinculada a su nombre indica ya, en realidad, el ejercicio de un poder constituido, esto es, ejercido por representantes que obran «en nombre» de la nación, pero que al final no dejan en ésta más que los efectos de sus actos. Y Sartre es bien consciente de que la nación es un «espejismo» en tanto que constituye la proyección hacia atrás de una unidad que existe sólo al nivel de la representación y de la unidad política incorporada en la soberanía estatal. Pero en el símbolo de la nación vibra todavía la experiencia del grupo en fusión. Así pues, por una parte Sartre lee en la «nación soberana» el producto artificial de una teoría; pero nos ayuda por otra parte a distinguir en la experiencia histórica aquello a lo que el símbolo remitía a pesar y en contra de la doctrina, así como también en oposición a las intenciones de quien lo había presentado.

\section{Aporía del juramento: fraternidad y terror}

El grupo en fusión obra por lo tanto contra un doble sí mismo: en oposición a su proyección representativa, y en contra de las dinámicas que él mismo lleva a cabo para sustraerse a la toma de la representación. 
Robespierre es el símbolo de todo esto, pero para comprender su figura histórica es necesario contextualizar su acción en la dinámica de los acontecimientos en los que participó. Del mismo modo sólo a través de las decisiones y las elecciones del individuo Robespierre resulta posible eliminar de los acontecimientos el aspecto fetichista que adoptan cuando su sentido se presupone a priori para subordinarlo a la lógica previamente constituida por una filosofía de la historia como la defendida por el marxismo dogmático contra el que Sartre polemiza en $Q M$. La Revolución es un terreno privilegiado para mostrar la irreductibilidad por un lado del obrar de los individuos y por otro del acontecimiento en su carácter concreto, complejo y «ambiguo».

De este modo Sartre discute con la historiografía marxista de la época que intentaba atribuir de manera clara las agrupaciones políticas y las elecciones de los protagonistas a factores de condicionamiento económico, a intereses «de clase» y semejantes. Pese a que se halla lejos de negar que estas cuestiones existan, el filósofo francés intenta mostrar cómo la historia no es comprensible sin tener en cuenta la autonomía de la acción y al mismo tiempo quiere hacer ver que la autonomía de la acción en la que el individuo determina lúcidamente sus objetivos no coincide en absoluto con la lógica del acontecimiento como condensación de tensiones y de fuerzas plurales y contrapuestas. Finalmente, y a diferencia de lo que ocurre en la filosofía de la historia hegeliana, no hay aquí en la obra ninguna «astucia de la razón». La historia carece de macrosujetos y su lógica es el resultado de la combinación de acciones de particulares y grupos cuyo sentido global debe necesariamente alejarse de los sujetos implicados sin que por ello resulte atribuible, ni siquiera desde la mirada retrospectiva del historiador, a instancias «ocultas» y operantes a espaldas de los protagonistas.

No es posible por tanto comprender la política de los girondinos haciendo de este grupo el simple emisario de intereses que habrían sido los propios de la «burguesía comercial» de la época, del mismo modo que no resulta factible atribuir a la extracción pequeñoburguesa de Robespierre su pasión por el universal. En lo referente a los «sans-culottes», Sartre ve en su ideología económica la presencia simultánea, contradictoria y al mismo tiempo real, de las concepciones del trabajo y de la propiedad características del Antiguo Régimen junto con una perspectiva abierta a las ideas del «individualismo posesivo» que alcanzarán la hegemonía a lo largo del siglo XIX.

Las medidas económicas adoptadas en el curso de la Revolución revelan una matriz eminentemente política e incluso los sans-culottes transforman sus necesidades de naturaleza material en objetivos de carácter político: el hambre se convierte en miedo a la contrarrevolución y es contra el enemigo imaginario siempre a las puertas contra el que se lanzan la jornada del $10 \mathrm{de}$ agosto que lleva a la caída de la monarquía, siendo éste un día que por la am- 
bigüedad misma de su resultado conducirá a las «matanzas de septiembre» ${ }^{24}$. Pero el reconocimiento de que «[...] la réalité politique, pour les hommes de 92, est un absolu, un irréductible» ${ }^{25}$ no significa que los factores económicos y sociales desaparezcan de la escena o pasen a segundo plano. Más bien al contrario, justamente el hecho de que su determinación se haga inmediatamente política permite entender por qué los conflictos presentes en la Revolución adquieren un carácter tan radical y totalizador. Si en este contexto «[...] la politique a par elle-même un sens social et économique $[. ..] \gg{ }^{26}$ entonces no sólo todo reduccionismo en sentido economicista se convierte en insensato, sino que incluso en el caso de fuera posible terminaría por ser superfluo. Es en la autonomía de la actuación política, y no en otro lugar, donde los contrastes entre naturaleza económica y social se presentan con todo el carácter concreto de su materialidad.

Justamente la atención a la dimensión política permite interpretar los discursos de los particulares y de los grupos en relación con el movimiento total que su acción imprime a la economía y a la sociedad, y también posibilita la dilucidación de la retroacción dialéctica que estos efectos ejercen en la posiciones de los primeros. Así por ejemplo la naturaleza inmediatamente política que la violencia de la necesidad adquiere en las reivindicaciones de los sans-culottes induce a la Montaña a obrar en sentido contrario a sus convicciones y a votar un primer decreto sobre el maximum el 4 de mayo de 1793. Según Sartre aquí aparece por primera vez la metáfora de la nación como «fortaleza sitiada» ${ }^{27}$ empleada por la Montaña para justificar estas medidas de carácter extraordinario que sin embargo no bastan para satisfacer las exigencias de los sans-culottes, quienes cuando «[...] vuelven a la Convención el 5 de septiembre de 1793 siguen teniendo hambre» ${ }^{28}$.

24 «Quand on se rappelle en outre que les sans-culottes, mystifiès par les instruments de pensée dont ils disposent, laissent transformer en violence exsclusivement politique la violence immédiate de leurs besoins matériels, on se fera de la Terreur une idée bien différente de la conception classique» ( $Q M$ 99). Acerca de las razones eminentemente políticas que habían guiado la acción de los girondinos en la proclamación de la guerra revolucionaria, cfr. pp. 42-48. Veremos subrayada la autonomía misma de la dimensión política en relación con los sucesos de la Convención.

[Ofrecemos la traducción española del pasaje citado en francés a pie de página: «Cuando se recuerde además que los sans-culotte, mistificados por los instrumentos de pensamiento de que disponen, dejan que la violencia inmediata de sus necesidades materiales se transforme exclusivamente en violencia política, podrá hacerse del Terror una idea bastante diferente de la concepción clásica», J. P. Sartre, trad. cit., vol. 1, p. 103 (N. de la T.)]

${ }^{25} Q M$ 44. [Damos aquí la traducción castellana de estas líneas: «[...] para los hombres del 92 la realidad política era un absoluto, un irreductible.», J. P. Sartre, trad. cit., vol. 1, p. 42 (N. de la T.)]

${ }^{26} Q M$ 44. [He aquí la traducción española de estas líneas: «[...] la política tiene por sí misma un sentido social y económico [...]», J. P. Sartre, trad. cit., vol. 1, p. 43 (N. de la T.)]

$27 Q M$ 96. [Véase J. P. Sartre, trad. cit., vol. 1, p. 99. (N. de la T.)]

${ }_{28} Q M$ 96. [Hemos tomado el texto citado en italiano por Gaetano Rametta de la traducción española del original francés: J. P. Sartre, trad. cit., vol. 1, p. 99 (N. de la T.)] 
Estamos en el origen del Terror. Por un lado, los sans-culottes no son capaces de ver que la razón de su miseria reside en última instancia en el rechazo por parte de la Convención de financiar la guerra mediante impuestos; por otro lado, la Convención misma debe alimentar el «espejismo» de que la mano de la contrarrevolución está tras la pobreza del pueblo, ya que de lo contrario habría de admitir el fracaso de lo establecido y condenar junto con esto toda la ideología del liberalismo económico. Así en la que Sartre llama «extraña jornada de los engaños» los leader de la Montaña - entre ellos Robespierre- - «[...] vont utiliser l'obscure colère populaire, dont les vrais mobiles sont économiques, pour appuyer une terreur politique: le peuple verra tomber des têtes mais il restera sans pain; la bourgeoisie dirigeante, elle, faute de vouloir ou de pouvoir changer le système, va se décimer elle-même, jusqu'à Thermidor, à la réaction et à Bonaparte» ${ }^{29}$.

Así resume Sartre, en síntesis, el destino de la Revolución en $Q M$. Pero, ¿cuál es el significado de este destino en relación con el grupo en fusión que hemos visto como protagonista de la toma de la Bastilla? Decíamos que, tras haber paseado entre las ruinas de la fortaleza derribada, el grupo debía combatir una doble proyección de sí mismo. Tenía que luchar, ante todo, contra la imagen que le devolvían las asambleas representativas: la Nacional, después la Constituyente, la Legislativa, la Convención. La cuestión relevante en todos estos casos no es la falsa dicotomía entre democracia representativa y democracia directa, sino las relaciones y las luchas entre grupos y particulares que, al obrar, se encuentran atrapados entre la voluntad de reactivar el grupo en fusión como motor propulsivo de la Revolución y la necesidad de proporcionarle una unidad de acción que no puede prescindir de la representación ni, sobre todo, de la mediación de lo que Sartre llama el «tercer regulador».

Este último, que hemos visto formarse en el grupo en fusión, pasa a ser protagonista también en el grupo que, a fin de sobrevivir al acontecimiento de su formación, se transforma en «organización» en tanto que reparto estructurado de deberes y funciones. En el nivel de la organización se desencadena la relación con la segunda proyección que coloca junto a los órganos representativos a organismos de diverso tipo: Tribunal revolucionario (10 de marzo de 1793, mismo día en que comienza la insurrección de la Vandea); Comité de vigilancia revolucionaria (21 de marzo); Comité de Salud Pública (5 de abril).

La Convención es el lugar donde la actividad de los actores entra en relación con los otros diputados, con el pueblo cuyas exigencias presionan más allá del espacio de la asamblea, así como con las decisiones que se toman en

${ }^{29} Q M, 96$. [Ofrecemos la traducción castellana de este pasaje: «[...] utilizan la oscura cólera popular, cuyos verdaderos móviles son económicos, para apoyar un terror político; el pueblo verá caer las cabezas pero se quedará sin pan; la burguesía dirigente, por su parte, al no poder o no querer cambiar el sistema, se diezmará a su vez, hasta Thermidor, hasta la reacción, hasta Bonaparte», J. P. Sartre, trad. cit., vol. 1, p. 100 (N. de la T.)] 
el tribunal y en las demás juntas. Según Sartre, para comprender lo que sucede en la Convención resulta necesario hacer referencia al carácter de «inercia jurada» (inertie assermentée) que condiciona la actividad de todo diputado particular en el momento mismo en que ésta es el fruto de una decisión libre y compartida por todos los miembros de la Convención. En el origen del juramento que vincula recíprocamente a los miembros de la Convención en la defensa a ultranza de la Revolución (en contra de los traidores como enemigos internos) y de la Patria (en oposición a las potencias extranjeras como enemigos externos) se halla el hecho traumático del 2 de junio con la purga de veintisiete diputados girondinos en la asamblea.

A partir de esta exclusión los integrantes de la Convención se encuentran libremente obligados a vincular su labor al respeto de lo que esta purga representa. La expulsión del Otro fuerza a que la voluntad general deje de ser considerada bajo el criterio de idea abstracta o, aún peor, de ideal regulativo. Deberá por contra prevalecer empíricamente en cada votación como práctica autoimpuesta de la libertad, asumiendo la unanimidad como único criterio de legitimación para las decisiones de la asamblea. En la unanimidad cada cual se reconoce como lo Mismo del Otro y ve en el Otro la imagen de la Nación una e indivisible remitida a sí mismo. Pero en esta afirmación de lo Mismo sin alteridad, es justamente la alteridad la que se reproduce en todo gesto particular, acción o palabra, ya sea conforme a las decisiones de la asamblea, a la praxis de los juicios revolucionarios o a las indicaciones del Comité de salud pública. Nadie puede actuar sin implicar a su organismo. Pero el propio organismo, justamente porque está tomado en su simple naturalidad, se convierte en el símbolo intolerable de una diferencia que, precisamente por quererse residual, no puede ser reabsorbida en la identidad del Mismo. Cada cual termina así por sospechar en sí al Otro bajo la máscara del Mismo y conjura para ello al único medio apto para extirparlo después de que todos los demás se hayan revelado vanos: la violencia de la Libertad-Terror.

No obstante, esta violencia no podría desencadenarse con toda su ferocidad de no ser el signo de una instancia todavía más profunda de la libertad: la Fraternidad sellada con el juramento. Es debido a que el hermano que he unido a mí mismo mediante el compromiso del juramento continúa ejerciendo como «tercer regulador» por lo que amenaza todavía la homogeneidad unánime del Mismo, debiendo por tanto ser suprimido. Pero para eliminarlo también yo debo actuar por mi parte como «tercero» mostrando con mi propio obrar que me aparto, que me mantengo a mi pesar como trascendente con respecto a la inmanencia radical en la comunidad, en la que también he jurado disgregarme. Hasta yo me convierto en sospechoso para mí mismo en el momento en que mi sospecha acerca del obrar de los otros y de sus intenciones más íntimas me lleva a emprender la vigilancia.

Reaparece la serialidad que hemos visto en el origen del grupo en fusión. Sin embargo, en la «toma de la Bastilla» la acción concertada espontánea- 
mente había transformado esta serialidad en condición productiva para la instauración del grupo en fusión, mientras que ahora la serialidad vuelve a surgir en el nivel de la institución como último intento de salvaguardar al grupo de la recaída en la serialidad misma: «Loin que la Convention réalise son unité à travers l'effort de ses comités pour l'unifier, elle devient un objet au point exact où la totalisation se brise la récurrence» ${ }^{30}$.

Así, el Terror lleva hasta sus últimas consecuencias la dialéctica del juramento y de la nueva fraternidad que él había inaugurado. El juramento constituía de hecho un nuevo nacimiento: cada uno de los conjurados nacía a una nueva vida en la comunidad sin depender ya de la contingencia de la naturale$\mathrm{za}$, sino creando libremente un vínculo que lo hacía hermano del otro. Ahora cada cual halla en sí el mismo organismo que le impide la disolución sin residuo en el grupo: una exigencia de la naturaleza viola el juramento que la había proclamado no esencial y amenaza con quebrantar la unidad fundada con tanto esfuerzo en favor de la multiplicidad orgánica de la pluralidad. Se hace por tanto necesario «[...] intentar liquidar al Otro como factor de inercia dispersiva y de desviaciones circulares; y como el Otro es cada uno en tanto que Otro, hay que imponer la fraternidad por la violencia» ${ }^{31}$. Pero tal y como acabamos de ver, esta supresión del Otro es imposible ya que éste «[...] no es más que cierta relación que se manifiesta precisamente en circunstancias que engendran al mismo tiempo la empresa de destruirla $[\ldots] \gg{ }^{32}$. Así pues, si en cada uno como Otro no puedo nunca afectar de una vez por todas, golpeándola, a la alteridad, tendré que intentar atacar en él aquello que lo convierte en el Mismo, es decir habré al fin de nadificarlo en tanto que subjetividad capaz de acción.

El Terror es la oscilación, a la vez eficaz e impotente, entre la anulación del Otro como el Mismo y la anulación del Mismo en tanto que irreductiblemente Otro. Se trata de una fluctuación eficaz ya que defiende a la «nación» de la recaída inerte en la serialidad. El Terror intenta combatir la serialidad tratando de transformarla de pasiva en activa y necesariamente, por tanto, en serialidad dirigida a la supresión de sí misma. Pero al final, eliminar serialmente la serialidad significa volver al Terror contra sí mismo en tanto que forma suprema de objetivación del grupo en fusión y realización última de su recaída en la objetividad serial. He aquí por qué quien ejerce el Terror es sospechoso ante todo para sí mismo; he aquí por qué la unanimidad de la Convención no será nunca suficiente; y también por qué tras haber depurado la

30 CRD 681. [Ofrecemos la traducción española de estas líneas: «La Convención no reali$z a$ ni mucho menos su unidad a través del esfuerzo de sus comités para unificarla, se vuelve objeto hasta el punto exacto en que la totalización se rompe contra la recurrencia», J. P. Sartre, trad. cit., vol. 2, p. 263. (N. de la T.)]

31 CRD 682. [Hemos ofrecido la traducción española del original francés citado en italiano por Gaetano Rametta: J. P. Sartre, trad. cit., vol. 2, p. 265. (N. de la T.)]

32 CRD 682. [Hemos dado la traducción castellana del original francés citado por el autor en italiano: J. P. Sartre, trad. cit., vol. 2, p. 265. (N. de la T.)] 
Convención esta purga deberá continuarse dentro del Comité de salud pública; se explica aquí, en fin, por qué la depuración sucederá en relación con los purgados mismos.

Con respecto a la lectura hegeliana, no se trata simplemente de una negatio negationis. Por una parte, es el Terror mismo el que transforma la organización del grupo en institución. El Terror se halla en las bases del Directorio y del Imperio ya que es la primera forma de institucionalización completa de lo que se había constituido en la «toma de la Bastilla» como «grupo en fusión». Por otra parte, el «espejismo» de la supervivencia del grupo en fusión es lo que anima las acciones de los Robespierre y de los Saint-Just y es por ello que Sartre comparte la tesis de quienes mantienen que el Terror comienza en realidad el 14 de julio y que de esa fecha hasta el 9 de Termidor conforma un todo con la Revolución ${ }^{33}$. En conclusión, el Terror no sería sólo lo que se elimina el 9 de Termidor, sino lo que permite éste y no porque de otro modo la Nación se hubiese autodestruido, sino porque justamente el Terror da origen a la institución como modalidad de supervivencia diferida del grupo en fusión que habitará siempre en ella como «fantasma» inquieto cuya aparición se temerá y conjurará a un tiempo. Será, por decirlo con una sola palabra, schmittianamente $\left\langle\right.$ retenida» ${ }^{34}$.

De este modo Sartre logra la reconstrucción de las «condiciones de inteligibilidad» que dirigen la constitución del Estado. A partir del juramento consiguiente al «enfriamiento» del grupo en fusión, el Terror aparece ya en acto porque es expresión del amor que me vincula al hermano y que exige el sacrificio desde el momento en que el amor que nos une es demasiado grande para poder soportar la separación del organismo. El «[...] poder difuso de vida y de muerte sobre el traidor o si se prefiere, la fraternidad-terror [...]» ${ }^{35}$ está ya en acto a partir del grupo en fusión, porque en las condiciones de éste aparece ya inscrita una dimensión de temporalidad que, al extender la experiencia en términos de «duración» entendida al modo bergsoniano (como temporalidad plena, densidad concreta y cualitativamente determinada de un acontecimiento por esto mismo irreversible) remite al momento del agotamiento de la acción en el objetivo alcanzado - en caso de éxito - o bien a la represión de la libertad en el caso opuesto. De aquí procede el monopolio de la «soberanía» por parte del Estado, en tanto que conjunto de instituciones que construyen sobre el «fantasma» del grupo en fusión los procedimientos de su legitimación y del espectáculo del «fantasma» desde su aparición en la escena pública.

33 Cfr. $C R D$, n. 2 , p. 683 s.

34 Se trata de una referencia a la interpretación de la figura del katechon en C. Schmitt, Der Nomos der Erde im Völkerrecht des Jus Publicum Europaeum, Greven Verlag, Köln, 1950. [Hay traducción española: C. Schmitt, El nomos de la tierra en el derecho de gentes del ius publicum europaeum, trad. de D. Schilling Thon, Comares, Madrid, 2003. (N. de la T.)]

$35 C R D$ 694. [Hemos ofrecido la traducción castellana del original francés citado en italiano por el autor: J. P. Sartre, trad. cit., vol. 2, p. 277. (N. de la T.)] 


\section{Sartre y Hegel}

En el curso de nuestro razonamiento hemos evocado varias veces el nombre de Hegel, quien cumple aquí una única finalidad, la de servir como elemento de comparación o parangón en relación con la interpretación dialéctica de la Revolución por parte de Sartre. El discurso de Sartre es de naturaleza exquisitamente filosófica, en el sentido de que atraviesa la experiencia histórica al nivel de la pregunta «crítica» acerca de las condiciones que hacen posible su inteligibilidad, y es por ello que nuestra interpretación del punto de vista hegeliano quedará justificada en la medida en que se concentra en la obra en la que se investiga la Revolución no tanto bajo el perfil de sus repercusiones en clave sociohistórica, como de su significado global vinculado a la adquisición de la conciencia de sí por parte del Espíritu. Habiendo explicado esta cuestión, queda claro que no es únicamente la inanidad del intento de contener en pocas líneas la interpretación total de la Revolución por parte de Hegel ${ }^{36}$ lo que en estas páginas nos induce a tomar exclusivamente en consideración la Fenomenología del Espíritu ${ }^{37}$, en la que la Revolución aparece como el momento culminante de la sección titulada «El espíritu extrañado de sí; la formación o Bildung». Es ésta la sección intermedia que sigue a la interpretación del mundo antiguo y que precede a la que Hegel dedicará a El espíritu seguro de sí mismo. La moralidad.

Se trata del celebérrimo pasaje de la «libertad absoluta a otro país o paisaje o ámbito del espíritu autoconsciente» ${ }^{38}$, es decir, de la Francia de la Revolución a la Alemania de la filosofía kantiana y de la nueva era que ésta inaugura en el reino del «pensamiento». Es notable que Hegel no hable, si examinamos lo que literalmente dice, de una transición general del «espíritu» de una región a otra, sino del hecho de que es «la libertad absoluta» (die ab-

36 Para una visión de conjunto $c f r$. C. Cesa, Hegel e la Rivoluzione francese, en C. Cesa, Hegel filosofo politico, Guida, Napoli, 1976, pp. 53-81. Para una profundización en los aspectos histórico-conceptuales cfr. G. Duso, Rivoluzione e legittimazione in Hegel, en AA.VV., Il concetto di rivoluzione nel pensiero politico moderno: dalla sovranità del monarca allo Stato sovrano, De Donato, Bari, 1979, pp. 139-204. Para encuadrar a Hegel en el contexto de la filosofía clásica alemana $c f r$. R. Bodei, Le dissonanze del mondo. Rivoluzione francese e filosofia tedesca tra Kant e Hegel, en F. Furet (ed.), L'eredità della Rivoluzione francese, Laterza, Roma-Bari, 1989, pp. 103-132. En relación con la red conceptual constituida por revolución, idealismo y democracia cfr. por último G. Rametta, Politica e democrazia nell'idealismo tedesco, en G. Duso (ed.), Oltre la democrazia. Un itinerario attraverso i classici, Carocci, Roma, 2004, pp. 175-208.

37 G. W. F. Hegel, Phänomenologie des Geistes, ed. de W. Bonsiepen y R. Heede, Gesammelte Werke, Bd. 9, Meiner, Hamburg, 1980, (de ahora en adelante cit. con la sigla PhG). [La versión española de los pasajes de la Phänomenologie des Geistes que aparecen citados por Gaetano Rametta en el texto siempre en traducción italiana, se ha tomado de la siguiente edición: G.W. F. Hegel, Fenomenología del espíritu, trad. de M. Jiménez Redondo, Pre-Textos, Valencia, 2006. (N. de la T.)]

$38 P h G$, p. 547. [G.W. F. Hegel, trad. cit., p. 701. (N. de la T.)] 
solute Freiheit) la que realiza y experimenta este paso. Además, este pasaje implica que la libertad misma ha aniquilado el reino de su «efectualidad», que ha destruido en suma toda forma de auto-objetivación a fin de poder hallarse, en su absolutez misma, en un reino completamente «inefectual»-el del pensamiento puro - donde poder reconocerse finalmente como realizada en su verdad. La verdad de la libertad absoluta consiste en resumen en su ser inefectual, en su relacionarse con toda forma de efectividad y de objetividad.

En este carácter negativo de la libertad encontramos ya sea una potencia ya sea su opuesto. Hallamos una potencia en tanto que la libertad muestra que no reconoce como efectivo nada que quiera afirmarse como independiente de ella. Se trata del movimiento de «nadificación» que Sartre intuyó como constitutivo de la «nación soberana». Pero descubrimos al mismo tiempo una incapacidad constitutiva en una libertad «absoluta» que al anular todo lo que se le opone imposibilita también cualquier forma de objetivación que proceda de ella misma. En resumen, la libertad absoluta no destruye sólo la objetividad de aquello que se presenta como obstáculo para su despliegue, sino también la posibilidad de toda virtual realización efectiva de sí. En este sentido, su relación con la efectualidad es doblemente negativa: es negación de la efectualidad como preexistente con respecto a su propia actividad (la sociedad estamental del Antiguo Régimen), pero es negación de la efectualidad también en el sentido de realización positiva de su actividad (la construcción de un nuevo Estado y de una renovada organización social). Su verdad es por tanto su propia inefectualidad o, si así lo preferimos, su irrealidad. Pero la comprensión de su irrealidad como su verdad se expresa de manera positiva justamente en la libertad «absoluta» como imperativo categórico de la moralidad. De este modo ya en Hegel la filosofía moral kantiana no es separable - al menos conceptualmente - del baño de sangre con el que el Terror celebra siniestramente el culmen de la Revolución.

A su vez el Terror, lejos de ser en la interpretación hegeliana un accidente histórico, lleva a cumplimiento aquel proceso de disolución de la realidad objetiva que había alcanzado, en las vísperas de la Revolución, una «efectualidad» propia que aparecía como rompedora en el desarrollo antinómico de una economía mercantil promotora y al mismo tiempo promovida a partir de la acumulación y de la circulación de la riqueza; y aspirante por tanto, a partir de la disolución de toda estructura, ya fuese ideal o real, a un reconocimiento de su estabilidad y permanencia.

En la terminología hegeliana tenemos el intercambio circular e incesante entre el «ser-en-sí» y el ser «fuera-de-sí» o «ser-para-otro». Se trata del movimiento del intercambio en el que no hay bien que no se produzca con la finalidad de intercambiarse por otros bienes a través de la mediación del dinero y con la finalidad de acumular este último. La naturaleza «en sí» del bien (su «valor de uso» habría dicho Marx) es atribuida a otro de sí, es decir, al «valor de cambio», puesto que la finalidad del objeto no consiste ya simplemente en 
satisfacer una necesidad, sino en subordinar la satisfacción de la necesidad a la acumulación de dinero como forma universal y eficaz de realización del valor. El objeto se convierte así en otro de sí y no sólo porque se utiliza para satisfacer las necesidades de la autoconciencia ni porque se intercambia por otros objetos, sino porque incorpora en sí mismo el ser-otro de sí. Es en sí mismo donde el objeto es «valor», esto es, «riqueza» abstracta susceptible de convertirse en dinero.

En este reino de la fungibilidad universal la inteligencia de la Ilustración reconoce su mundo y es por ello que el concepto de «útil» manifiesta la concepción dominante de la Ilustración en las vísperas de la Revolución. Sin embargo, en la noción de «útil» no tenemos todavía la disolución completa de la realidad objetiva. La inteligencia ilustrada se reconoce a sí misma en lo útil, pero todavía como objeto. El momento del «ser-para-sí» de la autoconciencia pura no ha conseguido aún asimilar y reducir a sí los otros momentos del ser-en-sí (consistencia objetiva de la «cosa») y del ser-para-otro (subordinación de la cosa al «intercambio» con otras cosas y a su utilización por parte del sujeto). La autoconciencia se ve reflejada en forma objetiva como movilidad universal, pero esta movilidad está aún unida a objetos y cosas.

En este sentido, lo útil constituye todavía un mundo para la conciencia. Pero, ¿qué tipo de mundo? Dado que en él se da la circulación y el intercambio recíproco de distintos momentos del en-sí, del ser para-otro y del para-sí, este «mundo» de lo útil ha sido ya privado de toda consistencia efectiva. Su núcleo no está constituido por algo que «se diluya», sino por el «diluirse» mismo. De este modo, Hegel podrá afirmar lapidariamente:

Sólo que, como las contraposiciones han aparecido [han salido a la luz] en la cúspide misma del concepto [o casi en la punta misma, o en la cúspide misma, que representa el concepto] o han ido a aparecer ahora, o han resultado salir ahora, precisamente en la punta que representa el concepto, la próxima etapa habrá de ser que esas contraposiciones se derrumben y se vengan abajo, y la Ilustración haga experiencia de los frutos de sus actos [Thaten, de los frutos de sus hazañas] ${ }^{39}$.

El Terror revolucionario es la expresión del ponerse de la autoconciencia pura como verdad objetiva de lo útil, el disolverse puesto «por sí» de todo residuo de consistencia y de objetividad que estaba ya incorporado «en sí» por lo útil, pero que en lo útil aparecía todavía como forma objetiva, esto es, como «mundo». El ponerse para sí de la autoconciencia, como verdad de la objetividad y actividad negativa de su «diluirse», comporta la anulación de todo lo que subsiste con independencia de la actividad de la autoconciencia y por tanto la conmoción de lo existente.

No obstante, resulta aquí necesario centrar la atención sobre el hecho de que, al tratarse precisamente de autoconciencia «pura», ésta no puede quedar

${ }^{39} P h G$, p. 530 [G.W. F. Hegel, trad. cit., p. 685. (N. de la T.)] 
satisfecha con una afirmación individual y determinada, que reproduciría el contraste entre el principio y la realidad. En tanto que «pura», la autoconciencia debe afirmarse necesariamente como universal, ya que sólo como tal puede demostrar que no le está subordinada únicamente esta o aquella determinación efectiva, sino el reino de la efectualidad en su totalidad. Asimismo a la inversa, la autoconciencia debe poner este reino como subordinado a ella no en este o en el otro aspecto particular, sino en tanto que realidad y objetividad tout court.

De este modo, en la Fenomenología del Espíritu el principio de la Revolución se interpreta como vinculado a la actividad de autoposición de una conciencia que no reconoce nada de existente ni de independiente con respecto a ella. Se trata de una autoconciencia en la medida en que la dimensión del ser-para-sí encuentra su realidad efectiva en el nivel de la individualidad y por tanto de toda conciencia individual. Por otra parte, es la conciencia en general, en tanto que principio universal de subjetivación de la realidad, la que debe hallar realización en cada una de las conciencias particulares.

Se repite entonces la aporía del universal y del particular que hemos analizado a propósito de Sartre. Pero, bien mirado, más allá de esta analogía formal meramente superficial, la estructura del razonamiento es muy diferente. Hegel puede permitirse prescindir de la naturaleza «común» del actuar en cuestión porque ha justificado la intersubjetividad en el paso entre el «momento» de la razón y el «momento» del espíritu. Al nivel del espíritu no nos hallamos ya en presencia de simples y puras «figuras» de la conciencia, sino de la configuración de «mundos» históricos que han incorporado la constitución de un obrar común. Y no obstante, justamente esta presuposición relativa le permite a Hegel trasladar las aporías de la Revolución a la relación entre universal y singular, esto es, a un desdoblamiento que inviste todas las autoconciencias, pero sólo en tanto que cada una de ellas es irreductiblemente singular. En otros términos, la aporía permite reconducir la dimensión específicamente política del actuar en «común» a la cuestión de la aceptación o no de una forma de representación, y localiza el centro de las dificultades, que Sartre habría puesto en relación con la temática del «grupo en fusión» y del «juramento», en la división que desgarra a toda autoconciencia singular entre su identidad como particular y el pensamiento del universal, que también la anima ${ }^{40}$.

40 «Tras la supresión y superación de las masas o esferas espirituales diversas, y [tras la supresión y superación] de la correspondiente limitada vida de los individuos [es decir, de la correspondiente limitación de la vida de los individuos a una de esas esferas] [...] no queda ahí ya, pues, otra cosa que el movimiento de la autoconciencia general en sí misma, como un juego de influencias recíprocas de ella misma con ella misma, en la forma de la universalidad [de un lado] y en la forma de la conciencia personal [de otro lado]. [...] Este movimiento es así un juego de acción y reacción de la conciencia consigo misma [...]» (PhG, p. 537). [G.W. F. Hegel, trad. cit., pp. 692-693. (N. de la T.)] 
Es evidente el influjo que el pensamiento de Rousseau ejerce en esta interpretación. Sin embargo, a nosotros nos interesa indicar de qué modo esta transcripción en clave rousseauniana de las aporías de la Revolución, como aporías que conciernen a todos en su aislamiento de conciencias divididas en su fuero interno entre los dos momentos indicados arriba, permite explicar otra diferencia significativa entre la lectura de Sartre y la del modelo hegeliano. Sintetizando al máximo: la clave proporcionada por Rousseau le permite a Hegel adoptar como léxico dominante de su interpretación el vocabulario de la voluntad como expresión subjetiva y al mismo tiempo universal de la libertad:

[...] [el espíritu es la autoconciencia que se aprehende a sí misma] en cuanto [o por el lado de que] la esencia [el en-sí, Wesen] y la realidad [Wirklichkeit] no lo es sino el saber de la conciencia de sí [el saber que representa la conciencia de sí, o el saber que la conciencia tiene de sí]. - La autoconciencia es consciente de [es sabedora de] esa su personalidad [Persönlich$k e i t]$ pura y en ella de toda realidad espiritual, y toda realidad es sólo elemento espiritual [es decir, cosa del espíritu]. El mundo le es a esa autoconciencia absolutamente su voluntad, y esa voluntad es voluntad universal o voluntad general [allgemeines Willen] ${ }^{41}$.

Está claro que esto plantea el problema de llevar la realización de la voluntad como voluntad general al mantenimiento de su «pureza» como voluntad universal. No nos ocuparemos aquí de realizar un nuevo examen de las aporías que Hegel pone de relieve y que han sido estudiadas numerosas veces por parte de los intérpretes. La singularidad es indispensable para la actuación de la voluntad, pero la voluntad general no puede tolerar la presencia de ninguna singularidad. Por ello, quienquiera que lleve algo a cabo, aunque sea luchando por la afirmación de lo general contra lo particular, estará obligado a particularizar el universal. De hecho, él mismo se muestra en su actuar como particular contrario a ese universal que querría sin embargo afirmar en su pureza. En este punto es justamente la contradicción entre su aspiración y su obrar lo que lo convierte en sospechoso, no sólo con respecto a la eficacia de su obrar, sino también en relación con la pureza misma de su anhelo. Al tratarse de un sujeto agente, es por definición un sospechoso, pero en la medida en que es sospechoso, se ha declarado ya culpable, dado que si hubiese sido verdaderamente conforme al universal, y por tanto inocente, nunca habría podido convertirse en sospechoso ${ }^{42}$.

41 PhG, p. 535. [G.W. F. Hegel, trad. cit., p. 690 (N. de la T.)]

42 Desde este punto de vista nos parece significativa la ambigüedad de la palabra «sospetto» en italiano en tanto que indica tanto la actividad de sospechar (sospettare) como el objeto sobre el que tal actividad se ejerce. Esta ambigüedad muestra que quien sospecha es ya siempre a su vez y en primer lugar para sí mismo sospechoso (sospetto). Aquí se abrirían evidentemente amplios márgenes para una lectura política de la obra de Kafka. [Hemos traducido esta nota a pie de página de Gaetano Rametta a pesar de que la ambigüedad que él señala en italia- 
De esta manera, quienquiera que actúe lo hace como particular usurpando la representación del universal; una representación que él mismo rechaza de palabra cuando aspira a actuar directamente como universal y que precisamente por esto usurpa cuando al declarar que obra como universal, muestra que lo hace como particular. Por tanto, no sólo no actúa por cuenta del universal y en su lugar, sino que lo hace directamente como facción contraria al universal mismo.

De este modo será sobre la base de los principios que rigen su acción como los jacobinos serán derrocados en el «golpe de Estado» de Termidor. Pero mediante la muerte, conminada como si fuese «cortar una cabeza de col, o tragar un sorbo de agua», la conciencia que ha sentido y soportado el «terror» de su «señor absoluto» puede de nuevo adaptarse a esa forma organizada de la negación que es la diferencia restaurada a partir de la libertad. Los individuos se reordenan en las «masas» diversificadas de la nueva organización social (primero bajo el Directorio, por tanto bajo el Imperio), y «[...] vuelven a su realidad sustancial [a la realidad sustancial de esas conciencias, vuelven esas conciencias a tener una realidad sustancial]» ${ }^{43}$.

El discurso de Hegel sobre la Revolución contenido en la Fenomenología del Espiritu se desarrolla entre los polos conceptuales de la voluntad y de la libertad. La libertad absoluta encuentra expresión en la voluntad general y la voluntad es general porque expresa la tensión por dominar la realidad por parte de una libertad que no tolera limitaciones y condicionamientos. Sin embargo, en la generalidad de la voluntad se manifiesta también el carácter común o «colectivo» del actuar del que se trata. No obstante, el rechazo de la representación le impide a esta libertad realizarse de manera positiva y el cortocircuito entre individuos empíricos y voluntad general hace volverse esta última en el carácter faccioso de una parte que ejerce su soberanía sobre los individuos que no le pertenecen actuando de la única manera que conoce. Administrando la muerte, esta parte lleva hasta el extremo esa «potencia de lo negativo» que, justamente por el carácter abstracto con el que se ejerce, no podrá más que invertirse sobre esa «parte» que usurpa, en tanto que gobierno, el nombre del «todo».

A la inversa, si comparamos el discurso de Sartre con esta lectura no puede menos que sorprendernos la ausencia casi total, en el filósofo francés, del léxico de la voluntad. Las aporías de la Revolución no se interpretan a la luz del cortocircuito entre «libertad absoluta» y «voluntad general», sino entre la libertad que emana del obrar en común del grupo en fusión y la fraternidad sancionada por el juramento del cual el individuo renace como «individuo co-

no no pueda trasladarse al castellano, lengua que cuenta con la distinción entre «sospecha»y «sospechoso». El término «sospechoso» («sospettoso») existe en italiano como adjetivo, mientras que para referirse a la persona jurídica del «sospechoso» cabe emplear, además de «sospetto», el vocablo «sospettato». (N. de la T.)]

$43 P h G$, p. 543. [G.W. F. Hegel, trad. cit., p. 698 (N. de la T.)] 
mún». La fraternidad es el único lugar en que la libertad puede ejercerse como libertad-terror y es sólo en tanto que yo mismo practico la libertad-terror como puedo impedirle al conjurado, que es mi hermano, que se traicione a sí mismo traicionándome a mí en tanto que su hermano.

Pero en la interpretación de Sartre el juramento aparece como necesario para evitar la muerte del grupo en fusión. El juramento parte de que el grupo existe y en este sentido no es un contrato, sino que presupone al grupo en tanto que ha sido y de este pasado quiere servirse para transformar el «estado» en condición estable para el futuro. El grupo que emerge del juramento sanciona de este modo su transformación en «grupo estatutario». Así, la libertad que se exhalaba en el grupo en fusión decide vincularse, a fin de salvarse, a un estatuto que le imprime de nuevo el sello serial de la inercia.

No por casualidad es en este nivel donde se sitúa, en opinión de Sartre, el paso del grupo a la «organización» y por tanto a la «institución». No obstante si, tal y como hemos visto, el estatuto del grupo que surge del juramento es ya de por sí el del «terror», esto significa que en el terror está el origen de la institución. A diferencia de lo que sucede en Hegel, el Terror no es sólo obra negativa y «furia de la disolución», sino constitución del grupo en organismo y por tanto fundamento «sustancial» del Estado que emerge de la Revolución. En Hegel, el Terror niega la Institución, mientras que en Sartre la «produce», consistiendo la diferencia de esta lectura en el hecho de que Sartre sustituye el léxico de la voluntad por el de la fraternidad; y cambia la aporía entre conciencia individual e instancia del universal por la aporía entre grupo en fusión que rechaza la recaída en la multiplicidad serial e inercia autoimpuesta de la libertad por el vínculo del juramento. Una interpretación de la Revolución en clave de filosofía del espíritu es reemplazada por una interpretación que lee la Revolución como «desvelamiento», a la vez emblemático y catastrófico, de las estructuras de sustentación del obrar común (Revolución como «Apocalipsis»). Desde la óptica sartreana la filosofía de Hegel se presta de este modo a la hipostatización en sujeto histórico de un «hiperorganismo» que le permite al concepto asimilar la historia en un proceso unitario, teleológicamente orientado a la actuación del «saber absoluto». El planteamiento «crítico» le impide en cambio a la razón dialéctica sartreana caer víctima de esta «ilusión»y distanciarse por tanto, al mismo tiempo, de las respuestas terroristas que la proyección ontológica de la praxis común ha conllevado históricamente y no en último lugar, como se ha visto, en la Revolución Francesa. 